\title{
Net Neutrality and Its Implications to Online Learning
}

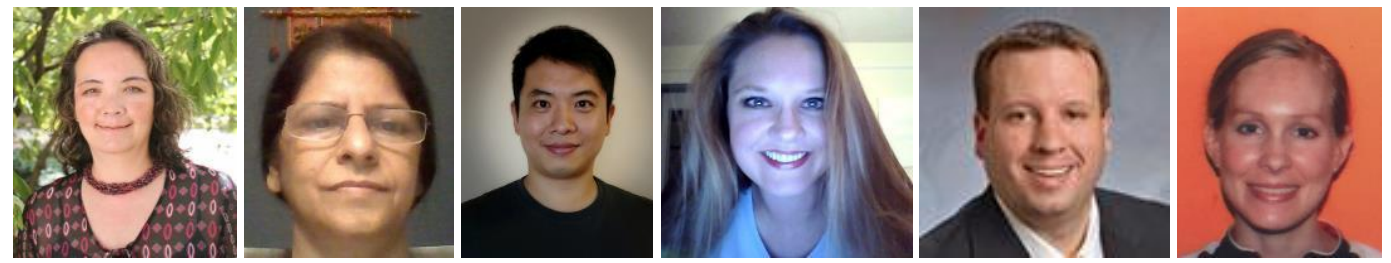

Lisa C. Yamagata-Lynch, Deepa R. Despande, Jaewoo Do, Erin Garty, Jason M. Mastrogiovanni, and Stephanie J. Teague

Educational Psychology and Counseling Department, University of Tennessee, Knoxville

\begin{abstract}
In this article, we studied net neutrality as a complex sociocultural phenomenon that can affect the works of distance education scholars and online learners. We decided to take part in this research because many distance education scholars and learners take net neutrality for granted. We engaged in a qualitative investigation of US public documents and explored the effects of net neutrality and public digital access, which can influence learner engagement with online educational materials. We focused on identifying tensions in the discourse about net neutrality, especially surrounding the Federal Communication Commission's (FCC) 2015 Open Internet Order. Our research question was: How do the complexities involved in the net neutrality debate in the United States affect public access to online information and services, and what implications does this hold for online learning? We relied on activity systems as an analytical framework for making sense of net neutrality.
\end{abstract}

Keywords: distance education access, computer mediated communication, net neutrality, digital divide, digital disempowerment, narrative analysis, activity systems analysis

\section{Introduction}

In the last couple decades, there has been a surge of distance education course/program offerings. These developments have been possible because both distance learning educators and learners have maintained a relatively equal access to the Internet. Many educators will agree that online learning provides access to flexible opportunities to learners who otherwise would not be able to advance their education (Graham, 2006). The Pew Research Center recently published a report that the findings suggest access to the Internet have positive influence to lifelong learning. They found that American adults who have access to technology tools are more likely to become lifelong learners and those adults rely on the Internet to access educational opportunities (Pew Research Center, 2016). They also found that adults who have both broadband and smartphone connections to the Internet are more likely to engage in personal and job- 
related learning activities to advance in their career than adults who have one mode of connection to the Internet.

The purpose of this study was to introduce net neutrality and its potential impact to online learning. We believe that if net neutrality is not in place, both distance learning educators and learners may find difficulty in engaging with online materials depending on where they live, personal finances, and what features they are willing to bundle into their cable services. Net neutrality regulatory decisions has significant influence on how US residents can access the Internet (Ganley \& Allgrove, 2006). We chose to engage in this research because for the most part distance education scholars have taken net neutrality for granted and have not investigated its implications to online learning. When net neutrality is not maintained, university administrators, staff, and faculty will not be able to ensure that their students will have equitable access to learning experiences in online courses. Instead, student access to online educational opportunities can be differentiated by how much they are able to pay a private cable or phone company and whether they live in a highly-populated city area or in less-populated rural area.

Our research question was: How do the complexities involved in the net neutrality debate in the United States affect public access to online information and services, and what implications does this hold for online learning? To address our question, we approached our research from a collective perspective, relying on Cultural Historical Activity Theory (CHAT) through activity systems analysis. We engaged in a qualitative investigation of US public documents and explored the effects of net neutrality and public digital access. Most documents we examined were from fields outside of education because the ongoing discussions have been taking place in areas such as economics, information science, law, and policymaking (see Choi \& Kim, 2010; Krämer, Wiewiorra, \& Wenhardt, 2013; Powell \& Cooper, 2011; Reinard \& Ortz, 2005). The goal of our analysis was to better understand the net neutrality regulatory and public debates and find how it is relevant to the future of distance education.

While there may not be abundant discussions in the current scholarly literature about net neutrality and its relevance to distance education, as researchers and practitioners we believe that net neutrality is a critical topic that need further examination by distance education researchers and practitioners. When we examined the literature to find commonly identified barriers for students taking advantage of distance education opportunities, we found that there were several conversations about learner skills, costs, and retention (e.g., Muilenburg \& Berge, 2005; Simpson, 2013; Taplin, Kerr, \& Brown, 2013). In one of the few publications we found that discussed net neutrality and its implications to distance education Brumfield (2010) examined factors that brought challenges to students in university environments. She found that online students felt most isolated from their learning community when they did not have access to library materials and they experienced difficulties with their Internet connection. This finding suggests that when online students have differentiated access to the Internet, they are likely to not be able to develop a sense of community and become less engaged with their learning experiences. In another article, McKee (2011) concluded that university educators and students need more information about Internet related policies to better understand their freedom to access information and be better prepared to take action when necessary. As a faculty in English, McKee provided suggestions on how net neutrality can be integrated into the undergraduate curriculum related to rhetoric and primary and secondary research. 
Net Neutrality is a timely topic to investigate because at the time of writing this article, media outlets are speculating that with a Republican president and majority in both houses of Congress, the regulations that promote net neutrality and digital equality put into place by the previous administration would be altered. In both liberal and conservative news outlets, such as the Forbes Magazine, New York Times, Washington Post, Wall Street Journal, and USA Today, there have been several articles and commentaries shortly after the 2016 presidential election speculating what could happen to net neutrality under the new administration. These articles and commentaries are in agreement that there will likely be changes that affect US residents' access to the Internet. These speculations are warranted because net neutrality regulations are heavily influenced by partisan politics: for the most part Democrats are in favor of net neutrality and Republicans are against net neutrality based on their antiregulatory principles (Hart, 2011).

\section{Net Neutrality as a Scholarly Discussion}

We chose to study net neutrality, specifically events surrounding the Federal Communication Commission's (FCC) 2015 Open Internet Order. While there is not a clearly articulated unifying definition to net neutrality, we developed our understanding of it from Wu (2003), which took a prominent role in crystalizing net neutrality as a socially shared phenomenon. Wu's work is generally accepted among scholars and net neutrality activists as a defining scholarly effort that popularized the term. Wu (2003) pointed out the potential consequences that US residents may experience as a result of challenges from the FCC's effort to protect consumer interests to access the Internet, while giving room for broadband companies to innovate both the technology infrastructure and services for the consumer. Our understanding of net neutrality is about maintaining equitable access to the Internet for all residents, by ensuring that they do not experience discrimination in services based on paid prioritizations.

The net neutrality debate itself is centered on whether to regulate or deregulate Internet Service Providers (ISPs), which are companies that provide high-speed Internet connection services to consumers. In this debate, it has been presumed that regulation will ensure free/less costly and equal public access to the Internet. On the other hand it has been argued that deregulation would give ISPs the power to differentiate services based on how much customers are willing to pay for their service. Therefore, regulation is intended to consider the best interests of US residents by guaranteeing nondiscriminatory access to electronic content (Lentz, 2013). ISPs that are against regulations argue that they need to rely on a differentiated pricing structure to secure the resources to maintain current services and invest in future innovative services (Lee \& Kim, 2014).

The debate may seem like it is solely a dichotomous argument between consumer rights and ISPs interest in profit, but it is far more complex. First, any conversation about media regulations in Western democratic nations is difficult because it is typically believed that government influence should stay out of the media (Puppis, 2010). However, in the case of net neutrality, government regulations are designed to ensure equal access to the Internet and to freedom of speech. Additionally, over the last several years, the economy surrounding the Internet has drastically changed. From an economic standpoint, the Internet is no longer a two-way system between consumers and ISPs and instead it involves the economic interests of content providers and advertisers as well as consumers and ISPs (Ma, Chiu, Lui, Misra, \& Rubenstein, 
2011). Finally, the drastic change in Internet application services that consumers need and want to access on a daily basis have become far more technologically sophisticated than the simple text data sharing system when the Internet was originally conceptualized. This requires ISPs to provide high bandwidth services that they were not initially required to deliver in the past (Lee \& Kim, 2014).

Bauer and Obar (2014) succinctly summarize why net neutrality has become a regulatory debate of high interest:

At the heart of the net neutrality debate is an institutional design problem: finding and implementing a set of governance mechanisms and broader governance regime that advances the benefits of the Internet as its technological, economic, and political conditions continues to evolve. (p. 1)

Bauer and Obar (2014) identified net neutrality as an institutional design problem because through public policy, nations are striving to find a government mechanism that will provide an environment where the public have equal access to the Internet and companies are willing to invest in developing innovative technologies with the intent to make profit.

Lentz (2013) engaged in a historical discourse analysis of FCC documents related to net neutrality surrounding the 2002 FCC ruling to deregulate broadband services, which effectively allowed broadband companies to be less concerned about protecting consumers from discriminatory treatment. Lentz's work uncovered how the FCC's current policy-making efforts about net neutrality were being affected by telecommunications legislative decisions in the 1960s. Her work demonstrated how the FCC's regulatory work over time involved a complex and politically charged linguistic exercise painstakingly bringing definitional meanings to telecommunication services that impact rule-making and policymaking. Therefore, despite the fact that the FCC encourages public input, net neutrality is a long established conversation with intense linguistic definitional exercises that make it difficult for the public including educators to become involved in a democratic process contributing to the general conversation about it.

In another study, Löblich (2015) examined documents and engaged in interviews about the 2009 and 2010 FCC Open Internet proceedings. In these proceedings the FCC considered whether there was a need for tighter regulations for broadband companies. Löblich presented net neutrality as a consumer advocacy issue because it "extends to the underlying infrastructure of the World Wide Web, and touches on a number of issues, such as communication rights, competition, market power, and consumer protection" (p. 3).

\section{Research Methods}

\section{Authorship Roles}

All authors took part in this research as part of an ongoing research team effort led by one faculty with several doctoral student members. The first, second, and third authors were involved in the entire 
research process for this work including the conception, data collection and analysis, and writing this article. Other authors were involved in the synthesis of findings and writing this article. All authors made significant conceptual contributions to the preparation of this article. There were graduate student research team members who contributed to the editing process of this article, but did not take a critical role in conceptualizing and writing the article to warrant an authorship. These research team members have been included in the acknowledgements.

\section{Data Collection}

Data collection and analysis took place during a 14-week period. Our data sources included public documents and media related to net neutrality including academic peer reviewed journal articles, news media publications, blogs, infographics, and government documents. We identified several criteria for identifying documents as part of our data. These criteria included: (a) peer reviewed journal articles about net neutrality, (b) news publications from outlets that have a practice of fact checking and editorial process, (c) articles published by activist groups often cited by other sources collected that have a practice of fact checking and editorial process, (d) corporate blog posts that are published with corporate branding and likely to have gone through editorial approval process, and (e) government documents related to net neutrality and the open Internet order. We collected 48 articles published on the web and 10 peer reviewed journal articles as the initial set of data. Reviewing this initial data set helped the team become informed about the general conversations in the net neutrality debate and to identify stakeholders who took a role in a publically shared narrative. We engaged in an additional targeted data collection of documents authored by various stakeholders and articles about net neutrality and the stakeholders. This resulted in 20 additional documents to the data set.

\section{Data Analysis}

We engaged in narrative analysis because narratives bring shape and form to ideas, allowing human beings to engage in ongoing dialog about ideas as part of reality (Bruner, 2002). Polkinghorne (1988) described that, "[n]arrative is the fundamental scheme for linking individual human actions and events into interrelated aspects of an understandable composite" (p. 13). The goal of our narrative analysis was to find meaning in the messy disjointed dialog about net neutrality surrounding the FCCs 2015 Open Internet Order. In this analysis, we focused on finding breach or trouble in the socially shared dialog that held the narrative together (Bruner, 1991; Daiute, 2011). We were interested in breach/trouble because it often represents socially shared challenges that organize human activity and help explain why individuals choose to participate in the socially shared activities (Yamagata-Lynch et al., 2017).

The first three authors engaged in a joint data coding process after initially reading and re-reading the data, which led to the identification of shared codes. At first, we worked individually examining the data. Then during our weekly research team meetings, we debriefed to each other potential codes and the definition for each code. In this process, we identified mutually exclusive definitions for each code that we agreed held the essence of main concepts we found in the narrative (Saldaña, 2016). Every week during subsequent team meetings we shared reflections on what new meanings we found in the narrative. Every time we engaged in a new iteration of data analysis we uncovered more depth to the stories in the narrative. This iterative analysis helped gain insights on values, policies, and the ideological perspectives 
held by various stakeholders (Daiute, 2014). We found that these stakeholders took a vital role in the historical development of the net neutrality narrative.

The first author took the lead in writing the initial draft of the narrative analysis results. She relied on the shared coding results, and reflective individuals and team memos. After the first author drafted the narrative findings, she shared it with team members and all members collectively edited for accuracy and at times went back to the data and individual memos to ensure that the narrative finding reflected both the essence of the narrative in the data and the collective understanding of the narrative shared by the team. We included original source data into the narratives as quotes where appropriate for readers to experience rich data.

After we agreed on a draft narrative finding, we engaged in activity systems analysis following its framework in CHAT. The unit of analysis in this type of work is the human activity, which involves a series of actions that affect the activity formation (Yamagata-Lynch, 2010; Leontiev, 1981). Activity systems as an analytical framework include subject, tool, object, rules, community, distribution of labor, and outcomes (Engeström, 1987; 1993) (see Figure 1). Subjects are participants of an activity and tools are the resources that subjects use to obtain the object or the goal. Rules can be policies, procedures, and beliefs that subjects are compelled to follow while engaging in an activity. The community is the group that subjects belong to and the division of labor is the shared responsibilities determined by the community. Finally, the outcome is the consequences that the subject faces as a result of the activity. Tensions are direct conflict between elements in the activity system that can make it possible for a participant to continue engaging in the activity, impossible to continue engaging in the activity, or change the nature of the activity (Cole \& Engeström, 1993; Engeström, 1987; Yamagata-Lynch, 2010). Tensions can become an obstacle for attaining the object or the reason why the subjects choose to modify an activity to attain the object (Engeström, 1993, Yamagata-Lynch, 2003).

We engaged in activity systems analysis by drafting and redrafting observed activity systems on poster paper while we discussed each element in the system that was represented in our narrative. For each iteration of drafting activity systems we used the following questions from (Yamagata-Lynch, 2010, p. 75) as a guide for identifying activity systems in qualitative data:

- What are the key activities related to this study that are in the data set?

- What is the activity setting in which these activities are situated?

- Who are the subjects of these activities?

- What is the shared object of these activities?

- Do different subjects participating in the same activity view the activity and the object differently? If yes, why?

- What tools, rules, community, and division of labor are involved in these activities?

- What systemic contradictions are bringing tensions into these activities? 
- What are the outcomes of these activities?

- What historical relationship does one activity have with another?

- How does one activity interact with another?

We initially identified several activity systems with different subjects and objects. We went back and forth between identifying activity systems and finalizing our narrative. In this process, we realized that the publically shared discourse about net neutrality involved a complex interwoven blend of activities with multiple subjects and contexts. We went back several times re-reading our data and eventually came to the conclusion that our data best represented net neutrality from the FCC's perspective. This was because in the historical progression of the net neutrality discussion we found that it was all organized in response to actions that the FCC took. Once we made this decision we searched for further information and obtained documents that discussed the FCC's values related to net neutrality, deliberation processes, and its historical decisions related to the Open Internet Order to ensure we understood the FCC as the subject in our analysis.

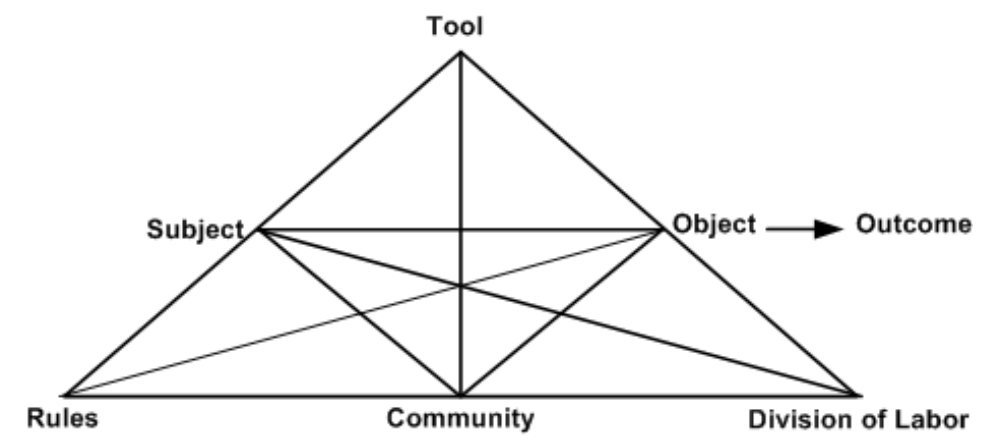

Figure 1. Activity Systems Analysis Model.

\section{Efforts for Maintaining Trustworthiness and Rigor}

Our primary method for maintaining trustworthiness was put into our effort working as a team. This research involved multiple investigators in every step and we relied on multiple sources of data to obtain a shared understanding about net neutrality (Lincoln \& Guba, 1985). To ensure that our research was a worthy topic, which is one characteristic of qualitative research with rigor (Tracy, 2010) we contextualized our research about net neutrality with public interest as our primary focus. To address what Denzin (1989) refers to as data triangulation, we included several forms of documents and media authored by various stakeholders with distinctly different interests in net neutrality at various times in its historical development. We addressed rigor in our data analysis (Tracy, 2010) by involving the first three authors in the multi-week data analysis process, and shared individual as well as collective findings during our team meetings. We shared with each other what made sense in the data and what did not so that we were able to identify new understandings about net neutrality, and chose which findings made sense to all of us 
after multiple iterations and warranted an inclusion in this report. Additionally, several other research team members participated in commenting on multiple drafts as we continued to write the article.

\section{Results}

\section{Narrative Findings}

Our findings are organized in narrative form from the results of the activity systems analysis. Drafting and redrafting the narrative led to our collective understanding of net neutrality as a complicated phenomenon. While it was difficult to pinpoint which historical event can be identified as the beginning of net neutrality as part of the public discourse, we found that the Telecommunications Act passed by the US Congress in 1996 had a significant role in net neutrality. The FCC information page for the Act describes it as follows:

The Telecommunications Act of 1996 is the first major overhaul of telecommunications law in almost 62 years. The goal of this new law is to let anyone enter any communications business-to let any communications business compete in any market against any other. The Telecommunications Act of 1996 has the potential to change the way we work, live and learn. It will affect telephone service-local and long distance, cable programming and other video services, broadcast services and services provided to schools. The Federal Communications Commission has a tremendous role to play in creating fair rules for this new era of competition. (FCC, 2013).

This law was put in place to encourage and incentivize US communications companies to enter an innovative technology business market by investing their money into building a network infrastructure all across the US territories. Congress put this Act into place with the assumption that if communication companies invested in building a network infrastructure then the US would take a dominant role in the future global economy.

To encourage communication companies to make this investment Congress chose to separate ISP from Telecommunication Carriers, and make ISPs exempt from the common carrier rules including neutrality (Chan, n.d.; Page, 2014). A common carrier classification would have made ISPs liable for neutrality because Internet services would have been treated a public utility (Maillé, Simon, \& Tuffin, 2016). While the FCC may have positioned themselves in the above narrative to take a significant role in putting fair rules in place (FCC, 2013), in reality, they had no regulatory authority over ISPs because they were not classified as a common carrier. In effect, ISPs were charged to innovate and take a lead role in entering a competitive Internet-based communications global market with no requirement for maintaining neutrality for the US residents.

Later in 2002, cable broadband companies were officially classified as ISPs. As ISPs, broadband companies were granted the right to practice light touch regulations under Section 706 of the Telecommunications Act, which allows them to self-regulate net neutrality with no government oversight (Quinn, 2014). This gave broadband companies a reason to invest their monies and build network 
infrastructure, which enabled US residents to have access to broadband services from their homes and places of work. As corporate investors, it did not make financial sense to invest their private monies laying down the cable for building the information superhighway if it were to be government controlled. Unfortunately, this created troublesome situations for consumers who complained to the FCC about corporate inequitable net neutrality practices, but the FCC could not legally sanction broadband companies. While this makes it seem like it is a simple matter, where ISPs are vilified when examining the historical developments, as we discovered in the net neutrality narrative, it became clear that it was not such a black and white matter.

Key stakeholders that we identified in the narrative included the FCC, and broadband companies such as AT\&T, Comcast, and Verizon; social activist groups such as Public Knowledge and Save the Internet; news media stories shared by comedian John Oliver, Newsweek, and Wired; Internet content and service provider companies such as Netflix, Facebook, and Google; and the US President. While engaging in data analysis we chose documents from all of the stakeholder groups above.

We found that Internet content providers and activities' groups were in alignment with the FCC's definition of Open Internet as stated below:

An Open Internet means consumers can go where they want, when they want. This principle is often referred to as Net Neutrality. It means innovators can develop products and services without asking for permission. It means consumers will demand more and better broadband as they enjoy new lawful Internet services, applications and content, and broadband providers cannot block, throttle, or create special "fast lanes" for that content. The FCC's Open Internet rules protect and maintain open, uninhibited access to legal online content without broadband Internet access providers being allowed to block, impair, or establish fast/slow lanes to lawful content. (FCC, 2015)

On the other hand, broadband companies may repeatedly state in their policies and corporate blogs that they are in support of the open Internet, and praise themselves for being bold, taking this position, when in several cases what they mean as open and neutral is very different from the FCC position. For example in February 2015 after the FCC ruling enforcing net neutrality by reclassifying broadband companies to telecommunications companies, the Executive Vice President and Chief Diversity Officer of Comcast shared the following in his blog:

We fully embrace the open Internet principles that have been laid out by President Obama and Chairman Wheeler and that now have been adopted by the FCC. We just don't believe statutory provisions designed for the telephone industry and adopted when Franklin D. Roosevelt was president should be stretched to govern the $21^{\text {st }}$ century Internet. (Cohen, 2015)

Open Internet in this instance for Comcast means open to the extent that is profitable for them, and with no regulatory authority from the FCC they get to decide how to regulate net neutrality. In the above narrative, Comcast is also trying to gain sympathy from consumers by continuing an argument instigated by other broadband companies that enforcing government regulation to communications companies is an ancient and out-of-date solution to tackle net neutrality for cutting edge technology. In fact, Verizon went 
a little further and posted their response to the FCC in typewriter font to remind consumers that we were going backwards in time. We found that broadband companies were deliberately attempting to change the focus of the narrative by shifting it from engaging in a dialog about what net neutrality is and how to protect consumers' best interest, to the government is taking us back in time which will inevitably slow the rate of progress in the broadband network technologies available to consumers.

\section{FCC Net Neutrality Activity}

In the FCC activity that was uncovered in our narrative analysis, the subject was the FCC, and we identified the object as ensuring net neutrality for all Americans. This object included the FCC's intent to promote and protect free expression, innovation, and investment in broadband networks. The tools for this activity were consumer interest shown in the over 4 million individuals commenting to the Open Internet Order; content provider support; and the Internet being identified as an essential part of American Life. However, the FCC had no regulatory authority over broadband companies for enforcing net neutrality. This became evident in the 2014 federal appeals court ruling related to Verizon when the DC Circuit Court determined that the FCC had no authority to enforce net neutrality rules because Verizon was not categorized as a common carrier.

In our analysis, we found that the historical events became part of the rules element because how they acted defined how net neutrality could be or could not be socially negotiated. The events that became part of the rules included the Telecommunications Act, Supreme Court Rulings, and FCC rules. There were two additional informal rules that we found took a critical role in the FCC activity. They were the light touch neutrality regulations and the political divide between the Democratic and Republican parties that had significant influence on the FCC membership and decision-making. The community with interest in net neutrality was a large group including consumers, Tim Wu, John Oliver, the US President, consumer activist groups, broadband providers, and content providers. The division of labor was another complex

component in the FCC activity where there were distinctly different roles played by the FCC, broadband providers, content providers, and consumers. 


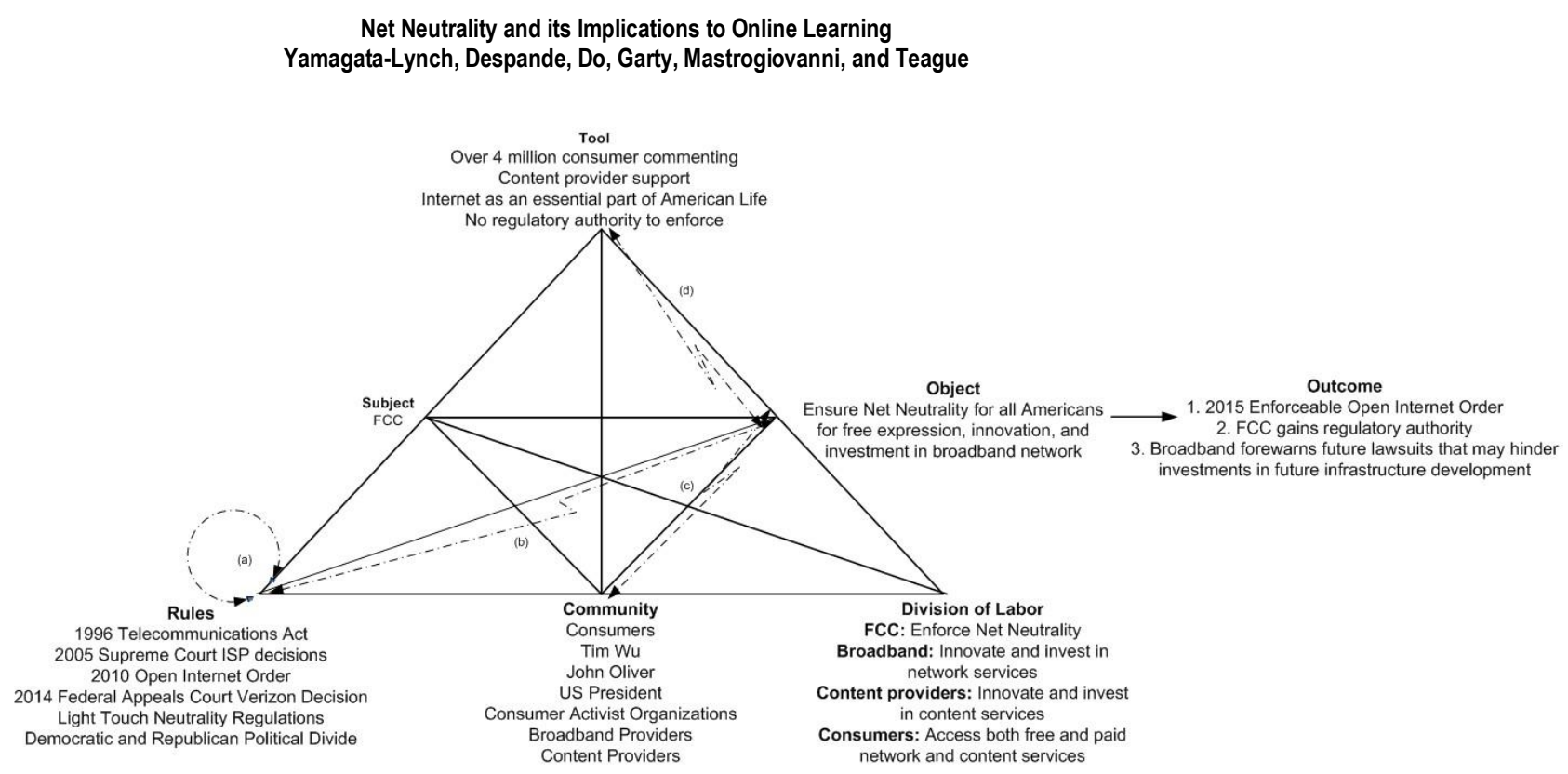

Figure 2. Analysis of the 2015 FCC Open Internet Order Activity. A previous version of the figure was published in Yamagata-Lynch et al. (2017).

\section{Identifying Tensions and Outcomes}

The four tensions we identified in the FCC net neutrality activity are summarized in Table 1. We identified these specific observations as tensions because they were a result of a direct conflict between elements in the activity system and each had significant influence on the FCC's ability to ensure net neutrality for all Americans, which was the object of the activity. The high number of tensions alone shows that the FCC activity was messy and complex weighed down by the interests of multiple stakeholders while protecting consumer rights to access information necessary in their daily lives. At the same time, the FCC needed to identify and enforce regulations that will help maintain an economic climate where broadband companies will be willing to continue investing in high-speed Internet communications infrastructure. Additionally, while the FCC had record breaking support from consumers based on the number of comments left on their website, the FCC had no regulatory authority to make any actions for protecting consumers. The consumer comments also revealed that some of them had an inherent distrust for any government agency involvement in communication media regulations.

Table 1

\section{Tensions in the FCC Net Neutrality Activity}

\section{(a) Rules $\rightarrow$ Rules}

FCC attempt to provide an environment for Broadband companies to invest and innovate in network infrastructure while ensuring net neutrality for all Americans

\section{(b) Rules $\rightarrow$ Object}

FCC attempt to ensure net neutrality for all Americans while working with rules that give them no regulatory authority, navigate political climate, and corporate agreements that encourage monopolization of Broadband services

\section{(c) Community $\rightarrow$ Object}

FCC attempt to ensure net neutrality while managing a divide in public mistrust in both government regulator and corporate entities 


\section{(d) Tool $\rightarrow$ Object}

FCC attempt to ensure net neutrality for all Americans with overwhelming support from the public while having no regularity authority

As a result of the FCC navigating the above tensions, the outcomes of the FCC net neutrality activity as of February 2015 was an enforceable Open Internet Order, where ISPs became reclassified as a common carrier. With this decision, the FCC gained regulatory authority over ISPs. This led to broadband companies forewarning of future lawsuits, which could affect their decisions for investing in future communication infrastructure development.

\section{Discussion of Results}

By investigating the net neutrality narrative in the US we found that it was an actively shared conversation among groups and individuals with diverse interest that often excluded everyday US residents. We found that the net neutrality narrative is indeed focused on policies and economic issues, but in any action taken, it had significant impact on public access to communication media (Ganley \& Allgrove, 2006). As a result, a lack of access to targeted regions and groups of people creates digital deserts that can introduce digital disempowerment to US residents who do not reside in highly populated areas (Hacker, Mason, \& Morgan, 2007).

We also found that US residents, who often experience firsthand the outcomes of the net neutrality public discussion, did not have much of a voice in the narrative itself. The active narrative contributors included government agencies such as the FCC, elected officials, private broadband companies, private contentproviding companies, public interest groups, court systems, academics, news media companies, and the general public. This makes net neutrality a complex, messy, and inaccessible activity to many US residents.

Within this context the FCC is the government agency that attempts to ensure a fair and equitable balance between safeguarding net neutrality for all US residents and supporting stakeholder investments in broadband network development. This task is not easy for the FCC because the sociocultural context in which net neutrality in the US is situated brings multiple tensions that act as barriers to the FCC activity. For example, arguments for ensuring that FCC has regulatory authority for guaranteeing nondiscriminatory network practices (Lentz, 2013) and the need to secure resources for maintaining network services to keep up with Internet innovations (Lee \& Kim, 2014) are both valid issues that need to be addressed.

\section{Implications to Online Learning}

Net neutrality regulations in the United States has an impact on how accessible online learning can be for current and future learners, and as a result what types of research distance education scholars may be able to engage in the future. When net neutrality is not maintained, disadvantaged learners can encounter structural inequalities that affect their access to information and experience digital disempowerment 
(Hacker, Mason, \& Morgan, 2007). Despite efforts by the US government to enhance educational opportunities for $\mathrm{P}-20$ learners through online learning, network discrimination is re-widening the gap for access to these educational opportunities (Gorski, 2009; Whitacre \& Mills, 2007). This can exacerbate existing social inequalities (Robinson et al., 2015). When social inequities and digital disempowerment becomes wide-spread, distance education scholars may find more opportunities to study the effects of inequities in Internet access to student learning; however, this is a research area that we do not necessary want to see growth if it can be avoided.

In the news, there are already examples of learner access issues to online educational materials based on socioeconomic status. For example, the "homework gap," which has been featured in recent news feeds, highlights digital inequity related to learner access to content. The homework gap is prevalent in lower income households in rural locations where families do not have broadband networks to access at home. As a result, school-aged children in these families often go to fast food chains, such as McDonald's, to complete their homework using public Wifi services (Horrigan, 2015; Troianovski, 2013).

In many cases, rural low-income families experience the homework gap because they live in digital deserts. These digital deserts are created when government regulations give room for broadband companies to choose not to invest in less lucrative markets. In 2015, the city of Chattanooga, Tennessee was featured in the news due to its efforts to eliminate digital deserts in nearby rural areas. The city government proposed providing residents with fiber optic high-speed Internet as part of public utility, but a state law written to protect broadband companies prohibited them from doing so (Melendez, 2015).

Issues related to the homework gap and digital desert may seem irrelevant for educational researchers who study online learning for adults. However, it can be inferred that learning management systems, MOOCs, open courseware, and games and simulations will all be affected when net neutrality is not maintained. We may find ourselves needing to work around an "Internet access gap" where not all online learners will be able to access course materials unless they come to a location with a high-speed Internet connection or pay high premiums. As discussed earlier in this article, Brumfield (2010) already found that online students in university settings feel isolated from their learning community when they do not have access to the library or have difficulties with the Internet. Therefore, distance education learners from low income families who may not have access to high-speed Internet connection will become systematically disadvantage learners in online classrooms.

\section{Conclusion}

We as authors are not advocating that regulation should or should not be in place. However, we find it as a necessity that distance education scholars become more familiar with net neutrality political, public, and regulatory discussions to better understand how net neutrality is already taking a critical role in the work that they engage. If educational researchers do not start taking part in discussions related to net neutrality, we may unknowingly contribute to solidifying the inequities surrounding Internet access that are already beginning to take shape in the United States. 
Bauer and Obar (2014) pointed out that net neutrality is an institutional design problem involving technology, economy, and policy. As a result of this study, we found one more layer of complexity in net neutrality as an institutional design problem. Based on consumer commenting data the FCC had recorded related to the 2015 Internet Order, we found that many consumers were not aware of the complexities and the tensions that take a critical role in the net neutrality debate. This did not give consumers an equal opportunity to engage in public discussions. Therefore, we believe that educational programs that help US residents understand the broader issues associated to net neutrality need to be put into place. Furthermore, educational researchers who are interested in online learning environments need further education about net neutrality as well as digital inequities.

This finding is similar to what McKee (2011) concluded, where she urged that university students and instructors need to become far more well informed about net neutrality and that it should be part of the curriculum. Education about net neutrality can help distance education scholars and their students better understand how their work can be heavily affected by net neutrality. This will provide an opportunity for online learning researchers and practitioners to determine whether the work they engage in is alleviating or exacerbating digital inequities. This will also help them identify how they need to be engaged with net neutrality debates as a professional as well as a private citizen.

\section{Acknowledgements}

We would like to thank our research team members who were not authors in this work including Ms. Anne Skutnik, Ms. Brenda Murphy, and Ms. Christie Patti for their continued editorial suggestions.

\section{References}

Bauer, J. M., \& Obar, J. A. (2014). Reconciling political and economic goals in the net neutrality debate. The Information Society, 3o(1), 1-19. doi:10.1080/01972243.2013.856362

Brumfield, E. J. (2010). Applying the critical theory of library technology to distance library services. Journal of Library \& Information Services in Distance Learning, 4(1-2), 63-71. https://doi.org/10.1080/15332901003765795

Bruner, J. (1991). The narrative construction of reality. Critical Inquiry, 18(1), 1-21.

Bruner, J. (2002). Making stories: Law, literature, life. Cambridge, MA: Harvard University Press.

Chan, Y. (n.d.). The history of net neutrality in the U.S [Blog post]. Retrieved May 5, 2015 from https://www.hstry.co/timelines/the-history-of-net-neutrality-in-the-u-s

Choi, J. P., \& Kim, B. C. (2010). Net neutrality and investment incentives. The RAND Journal of 
Economics, 41(3), 446-471. doi:10.1111/j.1756-2171.2010.00107.x

Cohen, D. L. (2015, February). FCC votes on new Open Internet rules [Blog post]. Retrieved from http://corporate.comcast.com/comcast-voices/fcc-votes-on-new-open-internet-rules

Cole, M., \& Engeström, Y. (1993). A cultural-historical approach to distributed cognition. In G. Salomon (Ed.), Distributed Cognitions: Psychological and Educational Considerations (pp. 1-46). New York: Cambridge University Press.

Daiute, C. (2011). Trouble-In, around, and between narratives. Narrative Inquiry, 21(2), 329-336.

Daiute, C. (2014). Narrative inquiry: A dynamic approach. Thousand Oaks, CA: SAGE Publications, Inc.

Denzin, N. K. (1989). The research act: A Theoretical introduction to sociological methods (3rd ed.). Englewood Cliffs, NJ: Prentice Hall.

Engeström, Y. (1987). Learning by expanding: An activity-theoretical approach to developmental research. Retrieved November 30, 2009, from http://lchc.ucsd.edu/MCA/Paper/Engestrom/expanding/toc.htm

Engeström, Y. (1993). Developmental studies of work as a testbench of activity theory: The case of primary care medical practice. In S. Chaiklin \& J. Lave (Eds.), Understanding practice: Perspectives on activity and context (pp. 64-103). New York, NY: Cambridge University Press.

Federal Communications Commission (FCC). (2013). Telecommunications Act of 1996. Retrieved October 8, 2015, from https://www.fcc.gov/encyclopedia/telecommunications-act-1996

Federal Communications Commission (FCC). (2015, March 12). Open Internet. Retrieved May 5, 2015, from https://www.fcc.gov/openinternet

Ganley, P., \& Allgrove, B. (2006). Net neutrality: A user's guide. Computer Law \& Security Review, 22(6), 454-463. doi:10.1016/j.clsr.2006.09.005

Gorski, P. C. (2009). Insisting on digital equity reframing the dominant discourse on multicultural education and technology. Urban Education, 44(3), 348-364. doi:10.1177/0042085908318712

Graham, C. R. (2006). Blended learning systems: Definition, current trends, and future directions. In C. J. Bonk \& C. R. Graham (Eds.), The handbook of blended learning: Global perspectives, local designs (pp. 3-21). San Francisco: Pfeiffer.

Hacker, K. L., Madon, S. M., \& Morgain, E. L. (2007). Digital disempowerment. In E. Rooksby \& J. Weckert (Eds.), Information technology and social justice (pp. 112-147). Hershey, PA: Information Science Publishing.

Hart, J. A. (2011). The net neutrality debate in the United States. Journal of Information 
Technology \& Politics, 8(4), 418-443.

Horrigan, J. B. (2015, April 20). The numbers behind the broadband "homework gap." Retrieved July 6, 2015, from http://www.pewresearch.org/fact-tank/2015/04/20/the-numbers-behind-thebroadband-homework-gap/

Krämer, J., Wiewiorra, L., \& Weinhardt, C. (2013). Net neutrality: A progress report. Telecommunications Policy, 37(9), 794-813. doi:10.1016/j.telpol.2012.08.005

Lee, D., \& Kim, Y. H. (2014). Empirical evidence of network neutrality - The incentives for discrimination. Information Economics and Policy, 29, 1-9. doi:10.1016/j.infoecopol.2014.07.001

Lentz, B. (2013). Excavating historicity in the U.S. network neutrality debate: An interpretive perspective on policy change. Communication, Culture \& Critique, 6(4), 568-597. doi:10.1111/cccr.12033

Leontiev, A. N. (1981). The problem of activity in psychology. In J. V. Wertsch (Ed.), The concept of activity in Soviet psychology (pp. 37-71). New York, NY: M. E. Sharpe.

Löblich, M. (2015). Dissent and political participation: The many faces of communication policy advocacy and activism. Communication, Culture \& Critique, n/a-n/a. doi:10.1111/cccr.12113

Lincoln, Y. S., \& Guba, E. G. (1985). Naturalistic inquiry. Newbury Park, CA: Sage Publications.

Ma, R. T. B., Chiu, D. M., Lui, J. C. S., Misra, V., \& Rubenstein, D. (2011). On cooperative settlement between content, transit, and eyeball Internet service providers. IEEE/ACM Transactions on Networking, 19(3), 802-815. doi:10.1109/TNET.2010.2089533

Maillé, P., Simon, G., \& Tuffin, B. (2016). Toward a net neutrality debate that conforms to the 2010 s. IEEE Communications Magazine, 54(3), 94-99. doi:10.1109/MCOM.2016.7432154

McKee, H. A. (2011). Policy matters now and in the future: Net neutrality, corporate data mining, and government surveillance. Computers and Composition, 28(4), 276-291. https://doi.org/10.1016/j.compcom.2011.09.001

Melendez, S. (2015). As big as net neutrality? FCC votes to kill state imposed Internet monopolies. Retrieved July 16, 2015, from http://www.fastcompany.com/3042895/as-big-as-net-neutralityfcc-takes-aim-at-state-imposed-internet-monopolies

Muilenburg, L. Y., \& Berge, Z. L. (2005). Student barriers to online learning: A factor analytic study. Distance Education, 26, 29-48. doi:10.1080/01587910500081269

Page, P. (2014). A brief, unfolding history of net neutrality [Infographic]. Retrieved May 5, 2015, from http://www.entrepreneur.com/article/235335 
Pew Research Center. (2016). Lifelong learning and technology. Retrieved from http://www.pewinternet.org/2016/03/22/lifelong-learning-and-technology/

Polkinghorne, D. E. (1988). Narrative knowing and the human sciences. Albany, NY: State University of New York Press.

Powell, A., \& Cooper, A. (2011). Net neutrality discourses: Comparing advocacy and regulatory arguments in the United States and the United Kingdom. The Information Society, 27(5), 311-325. doi:10.1080/01972243.2011.607034

Puppis, M. (2010). Media governance: A new concept for the analysis of media policy and regulation. Communication, Culture \& Critique, 3(2), 134-149. doi:10.1111/j.1753-9137.2010.01063.x

Quinn, B. (2014, July 17). Banning paid prioritization within a viable and sustainable framework [AT\&T Public Policy Blog]. Retrieved from http://www.attpublicpolicy.com/fcc/banning-paidprioritization-within-a-viable-and-sustainable-framework/

Reinard, J. C., \& Ortiz, S. M. (2005). Communication law and policy: The state of research and theory. Journal of Communication, 55(3), 594-631. doi:10.1111/j.1460-2466.2005.tbo2687.x

Robinson, L., Cotten, S. R., Ono, H., Quan-Haase, A., Mesch, G., Chen, W., ... \& Stern, M. J. (2015). Digital inequalities and why they matter. Information, Communication and Society, 18(5), 569582. doi:10.1080/1369118X.2015.1012532

Saldaña, J. (2016). The coding manual for qualitative researchers (3rd ed.). Los Angeles, CA; London: SAGE Publications Ltd.

Simpson, O. (2013). Student retention in distance education: Are we failing our students? Open Learning: The Journal of Open, Distance and E-Learning, 28(2), 105-119. doi:10.1080/02680513.2013.847363

Taplin, R. H., Kerr, R., \& Brown, A. M. (2013). Who pays for blended learning? A cost-benefit analysis. The Internet and Higher Education, 18, 61-68. doi:10.1016/j.iheduc.2012.09.002

Tracy, S. J. (2010). Qualitative quality: Eight "big-tent” criteria for excellent qualitative research. Qualitative Inquiry, 16(10), 837-851. doi:10.1177/1077800410383121

Troianovski, A. (2013, January 29). The web-deprived study at McDonald's. Wall Street Journal. Retrieved from http://www.wsj.com/articles/SB10001424127887324731304578189794161056954

Whitacre, B. E., \& Mills, B. F. (2007). Infrastructure and the rural-urban divide in high-speed residential Internet access. International Regional Science Review, 3o(3), 249-273. doi:10.1177/0160017607301606 
Wu, T. (2003). Network neutrality, broadband discrimination. Journal on Telecommunications and High Technology Law, 2(1), 141-176.

Yamagata-Lynch, L. C. (2003). Using activity theory as an analytical lens for examining technology professional development in schools. Mind, Culture, and Activity, 1O(2), 100-119. doi:

10.1207/S1532-7884MCA1002_2

Yamagata-Lynch, L. C. (2010). Activity systems analysis methods for understanding complex learning environments. New York: Springer.

Yamagata-Lynch, L. C., Do, J., Deshpande, D., R., Skutnik, A. L., Murphy, B., \& Garty, E. (2017). Narrative inquiry with activity systems: A story about net neutrality. International Journal of Qualitative Methods, 16(1), 1-11. doi.10.1177/1609406917704352

\section{Athabasca} University

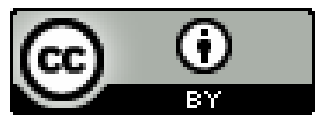

